\title{
CORRIGENDUM
}

\section{Bedside RNA stabilizing kit systems for gene expression analysis of acute leukemias: influence of non-neoplastic white blood cells}

\author{
A Zebisch ${ }^{1}, \mathrm{~W}$ Linkesch $^{1}$ and $\mathrm{H}$ Sill ${ }^{1}$ \\ ${ }^{1}$ Division of Hematology, Department of Medicine, Medical University of Graz, Graz, Austria
}

Leukemia (2005) 19, 685. doi:10.1038/sj.leu.2403713

Correction to: Leukemia (2005) 19, 136-137.

doi:10.1038/sj.leu.2403581
The authors have identified an error on the $x$-axis of Figure 1 . The correct figure is reproduced below.

The authors apologise for any inconvenience this might have caused.
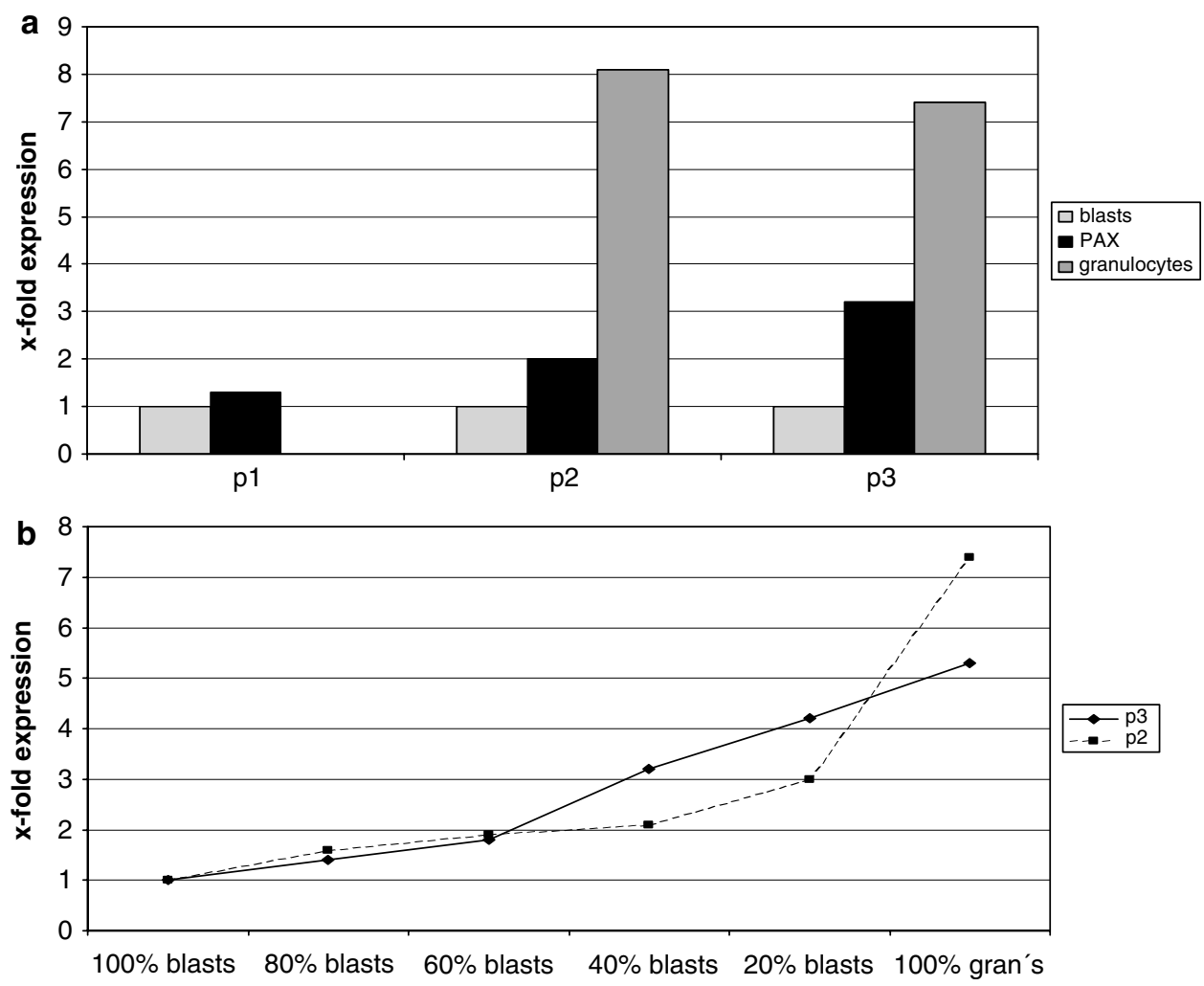

Figure 1 (a) Different C-RAF expression in the three patients (p1-3) in granulocytes, myeloblasts and RNA isolated in the PAXgene blood RNA system. Blast percentage was $98 \%$ in p1, 70\% in p2 and $20 \%$ in p3, respectively. (b) Serial dilution experiment. Pure blast cell RNA of patients showing differences in C-RAF expression in blasts and PAXs (p2 and p3) was serially diluted with granulocytic RNA of the same patients and subjected to expression analysis. 